\title{
Considerations regarding the relationship between environment, health and life quality
}

\author{
Daniela Cîrţînă ${ }^{1}$, Valentin Nanescu ${ }^{1}$ \\ 1"Constantin Brâncusi” University of Targu-Jiu, Faculty of Medical and Behavioral Sciences, \\ No. 4, Tineretului St., Targu-Jiu, Romania \\ E-mail: danielacirtina@gmail.com
}

\begin{abstract}
This paper presents aspects related to how the factors that define the environment, such as physical, chemical, biological and social factors directly or indirectly exert their influence on human health related quality of life. The phenomenon of air, water, soil pollution, radiation exposure, unhealthy diet, nutritional and microbiological quality of food are elements that have consequences on life quality.
\end{abstract}

Keywords: environment, health, life quality

\section{Introduction}

Different ways of defining the quality of life are known, but it can be appreciated that regardless of the meaning, the quality of life is closely related to the environment. The interaction between the natural environment and the quality of life has led to the need of studying health problems and the appearance of some diseases in certain social, climatic, biological and psychological circumstances in which humans lives and works.

Life quality has been medically defined as physical, mental, and social wellbeing, as well as the patient's ability to perform their usual tasks in their daily lives. A definition given by the WHO in 1998 presents the meaning of life qualityas given by the perceptions of individuals on their social situations, in the context of the cultural value systems in which they live and depending on their own needs, standards and aspirations. Another definition given in 1993 by Revicki \& Kaplan is that "life quality reflects the preferences for certain health conditions that allow improvements in morbidity and it is expressed by a single weighted index - standardized life years, depending on the quality of life". $[1,2]$

The factors that define the environment, physical, chemical, biological and social factors can influence people's health, part of life quality. The phenomenon of air, water, soil pollution, radiation exposure, unhealthy eating, nutritional and microbiological quality of food are just a few examples of factors that have consequences on the quality of life. There is a set of conditions and elements that have an impact on the health of people and the general population. [3,4]

Currently, both sanogenic (health) and aggressive (human pathogens) factors are being studied, which mainly affect the age groups most sensitive to these factors - children and the elderly. The research shows that fast changes in the ecosystem lead to a much difficult ability of the human body to adapt to the new living conditions. In order of their importance, environmental risks to human health can be classified into three main categories. The high environmental risks represent the first category that includes elements such as dangerous meteorological phenomena, the ozone depletion, the degradation of natural habitats and the reduction of biodiversity. The second category is represented by the medium risks that include phenomena such as: acid rain, pollution of water with toxic substances, the impact of 
greenhouse gases, soil pollution with pesticides and the radioactive pollution of the environment. Thermal and noise pollution are forms of pollution with low health risk. [4,5]

\section{Drinking water and ambient air quality and the health risks}

There are a number of substances and concoctions considered to be dangerous for the environment and implicitly for health, substances that, if they penetrate in the environment present or could present in certain conditions an immediate or delayed risk. The quality of life can be influenced by toxic substances and concoctions which, by inhalation, swallowing or penetration through the skin, can cause acute or chronic health disorders. The environmental risk assessment includes, as an important component, the monitoring of persistent organic pollutants, heavy metals, biocidal products and plant protection products, substances that degrade the ozone layer. The presence in the environment of ionizing radiation, carcinogens, irritants or oxidants substances can produce effects starting with altered health to serious diseases of the human body. Through the harmful effects of pollutants on the main environmental factors, there are created conditions that have a direct influence on the health and life quality. [4, 6-8]

Drinking water must not be harmful to the human health, therefore it must not contain pathogenic bacteria. The large amount of water used centrally by the population presents the risk, that under pollution conditions, water can be an important factor of disease. Waterborne diseases can include a large number of people, and can be mass-spreading. Thus, in order to obtain drinking water, natural water is subjected to operations such as decantation and filtration, which aim to reduce the suspended substances. By settling and filtering, the number of microbial germs that are in the water is greatly reduced without, however, achieving the bacteriological conditions required by a drinking water. Although that water decantation and filtration greatly reduce the quantity of microorganisms in the water, do not, however, give a full guarantee of their final removal, which is why water sterilization is applied. This is done in all cases where the water supply source is not sanitary safe. Water disinfection can be performed by chemical methods (chlorine treatmentand chlorogenic substances, ozone, potassium permanganate etc.) and physical methods (distillation, boiling, ultraviolet radiation, ionizing radiation, ultrasonic). $[4,8,9]$

Drinking water quality can be an important factor in the transmission of diseases among the population. Waterborne diseases can be infectious diseases (bacterial, viral, parasitic) and non-infectious diseases. The category of bacterial diseases includes: typhoid fever caused by the bacillus (Salmonella typhi). The disease is specifically human, the germ being eliminated from the human body once with the ingested water, dysentery caused by dysenteric bacilli (Shigella disenteriae) and cholera is another digestive bacterial disease in which water plays a major role.

The viral diseases are polio and epidemic hepatitis. The high danger of spreading polio is based on the fact that polio viruses have a high resistance in the environment, in the water they survive 150-180 days.

In the case of parasitic diseases, water plays a dual role in their transmission. On the one hand, for some parasitic diseases, water has a passive role, namely to serve as a path of transmitting the parasite from the sick or carrier to the healthy person, as in the case of bacterial or viral diseases, and on the other hand, water it is a mandatory environment without which they cannot complete their evolutionary cycle or in other words, they cannot reach the stage of disease production. Amoebiasis or amoebic dysentery is the most common waterborne parasitosis. The parasite is eliminated in the external environment in the form of a cyst, which gives it a high resistance. Another example is lambliasis or giardiasis caused by lamblia or giardia intestinalis. The parasite is also eliminated in the form of a cyst resistant to external environmental factors; in the water it survives for several months. The disease occurs mainly through the ingestion of infested water and less often through food. Trichomoniasis is a parasitosis in which transmission water plays an important role, along with the direct interpersonal contact. [8-10]

Water can also transmit a series of non-infectious diseases caused by polluted water, including endemic goiter or thyropathic dystrophy. This is a mass-spreading disorder which leads not only to a large number of cases but also to endocrine complications. As it is known, iodine is a natural constituent 
of the thyroid gland, being the essential element of thyroid hormone. Iodine deficiency is the cause of endemic goiter as a result of pituitary stimulation due to thyroid hormone deficiency. The goiter has a serious character, up to forms of cretinism and deafness, at concentrations below 2-3 $\mu \mathrm{g} / \mathrm{dm}^{3}$ of water. Other examples can be nitrate poisoning that causes methemoglobinemia, with lead (lead poisoning), mercury poisoning that has symptoms of headache, dizziness, insomnia, memory and visual disturbances and even teratogenic effects. To all of these, can be added cadmium poisoning that has effects on the liver, produces anemia, decreased of calcium, arsenic poisoning that causes metabolic and digestive disorders, headaches, dizziness etc., fluoride poisoning that can have dental, bone and kidney forms. At high concentrations of fluorine (above $5 \mathrm{mg} / \mathrm{dm}^{3}$ of water) fluoride acts on the bones, producing a significant increase in opacity to X-rays. At even higher concentrations (over $20 \mathrm{mg} / \mathrm{dm}^{3}$ of water) there are changes in bone composition with increasing the amount of fluoride in the detriment of calcium. $[10,11]$

Ambient air quality has an important role in triggering certain diseases and can influence the wellbeing and generate a deterioration in quality of life. Air pollutants can be grouped according to their health effects. Thus, we have irritating pollutants such as sulfur oxides, nitrogen oxides, sedimentable or suspended dusts. The powders act on the airways that can be affected by inflammation, rhinitis, pharyngitis, laryngitis, bronchitis or alveolitis. The sulfur dioxide, resulting from the burning of fossil fuels and industrial processes, is considered to be the main harmful substance in the air. The effects of the sulfur dioxide on humans are manifested primarily by a respiratory irritation, salivation, expectoration, spasms and breathingdifficulty that can lead to chronic bronchitis. The synergism of the sulfur oxides with other pollutants present in the atmosphere, leads to new physiological reactions.

The nitrogen oxides produce at the level of the airways the cilia of the bronchial and tracheal epitheliamovementsblocking. At the blood level it combines with hemoglobin resulting in methemoglobin which prevents the transport of the oxygen to the tissues. The asphyxiating pollutants include those substances whose predominant pathogenic effect is hypoxia or anoxia by blocking the supply, transport or use of the oxygen in the metabolic processes. Of these, the most common air pollutant is the carbon monoxide, resulting from incomplete combustion, it combines with hemoglobin generating a lack of oxygen with the most serious consequences, headaches, dizziness, drowsiness, nausea, arrhythmias etc. $[9,10,11]$

The fibrous pollutants contain a group of substances that penetrate the lung causing a fibrous reaction by complex mechanisms, specific to each substance. The dusts persists in the lungs, causing a decrease in the elasticity of lung that leads to fibrosis. The systemic pollutants are very numerous, coming mainly from industrial processes and means of transport. The lead is an environmental pollutant that can enter into the human body along with food or water. The population exposure to lead can be professional or unprofessional. Released into the atmosphere in vapors form that condense quickly, it can enter into the human body through the respiratory or digestive tract. The harmful action takes place at the blood level, anemia occursat the nervous system level as well, it causes a slowdown in the intellectual development in children. Penetrated into the circulation, the lead is found in small amounts in plasma, most part of it is fixed in the red blood cells. The lead is mostly stored in the bones, especially in the long bones. The carcinogenic pollutants - in case of prolonged exposure, polycyclic aromatic hydrocarbons resulting from incomplete combustion of solid and liquid fuels are concentrated in the human body. Carcinogenic substances are also arsenic, chromium, beryllium, cobalt, selenium, elements present especially in industrial environments. The allergic pollutants are responsible for increasing the frequency of allergic diseases, and especially respiratory allergies. The main allergenic factors in the atmosphere are natural products such as pollen, fungi or volatile products came from certain plants. The list can continue with the pollutants with infectious action represented by various pathogenic germs that can be found in the atmosphere.

The air plays an important epidemiological role, constituting the transmission route for a large number of pathogens. Infectious diseases that are transmitted through the air are childhood diseases (measles, rubella, scarlet fever, chicken pox etc.) the flue and other respiratory viruses, microplasmosis, diphtheria, smallpox, tuberculosis, pneumonia, various respiratory mycoses etc. There are diseases that, 
in addition to other routes of transmission, can spread by air, such as polio, tularemia, or less often, plague, coal etc. Also, the pathogenic flora or conditioning pathogenicflora from the air can cause wound or burn infection. The survival of the pathogenic or conditionally pathogenic germs in the air depends on a number of factors. In general, the air does not offer conditions for the development of the microflora of human origin, their survival being limited by the existence of unfavorable conditions. In the air there is no nutritional support for microorganisms that parasitize human or animal organisms. To these unfavorable factors is added the existence of agents with bactericidal or bacteriostatic action, of which the most important is the ultraviolet radiation. [10-12]

\section{Conclusions}

The most known impacts on health and implicitly on the quality of life refer to the pollution of the ambient air, to the inadequate quality of the water and to the insufficient hygiene. There are a number of categories that contain chemicals substances dangerous to the human health, substances and preparations that present, directly or through the interactions they have, risks of disease to the population. In the natural environment there are conditions and elements that, taken separately or as a whole, have an impact on human health and on the population, generally. Drinking water quality can be an important factor in the transmission of diseases among the population. Waterborne diseases can be infectious diseases (bacterial, viral, parasitic) and non-infectious diseases with symptoms. Through the presence in the air of various pollutants with irritating, asphyxiating, carcinogenic, allergenic action, there are created conditions that have a directly influence on the health and quality of life. The air plays an important epidemiological role and is the path by which numerous pathogens are transmitted. Bacteriological analysis of the air allows the hygienic characterization of the potential that the environment has in the aerogenic transmission of the infections.

\section{References}

[1] Berca, M., General ecology and environmental protection, Ceres Publishing House, Bucureşti, 2000.

[2] Ciolpan, O., Integrated monitoring of ecological systems, ArsDocendi Publishing House, Bucureşti, 2005.

[3] Ghizdavu, L., Bioinorganic chemistry, Ed. Poliam Cluj Napoca, 2000.

[4] Săndoiu, I.F, Integrated monitoring of ecological systems, MatrixRom Publishing House, Bucureşti, 2013.

[5] Vitaku, A., Baruti, B., Malollari, I., Shala, F., Journal of Environmental Protection and Ecology, Vol.14, No. 1, Thessaloniki Greece, 2013, p. 29-34.

[6] Traistă E., Madear G., Environmental hygiene. Air and water hygiene, Universitas Publishing House, Petroșani, 2000.

[7] Capatina, C., Simonescu, C.M., Journal of Environmental Protection and Ecology, 2, 2009, p. 313.

[8] Popa, P., Patrichie N., Chemistry of the aquatic environment. General elements of hydrochemistry and ecotoxicology, Ceres Publishing House, București, 2001.

[9] Iordache, V., Ardelean F., Ecology and environment protection, MatrixRom Publishing House, București, 2007

[10] Cîrțînă, D., Traistă E., Traistă C., Danciu C., Environmental sanitary chemistry, Academica Brâncuși Publishing House, Tg-Jiu, 2017.

[11] Dinu V., Truţia E., Cristea-Popa E., Popescu A., Medical biochemistry, Bucureşti, 1996.

[12] Mănescu S., Cucu M., Diaconescu M. L., Environmental health chemistry, Medicală Publishing House, Bucureşti, 1994. 